\title{
Association between asthma control and bronchial hyperresponsiveness and airways inflammation: a cross-sectional study in daily practice
}

\author{
V. Quaedvlieg, J. Sele, M. Henket and R. Louis \\ Department of Respiratory Medicine, GIGA Research Center, CHU Liège, I I Group, University of Liège, Liège, Belgium
}

\begin{abstract}
Summary
Background The primary end-point in the management of asthma is to obtain optimal control. The aim of this study was to assess the relationships between the markers of airway inflammation (sputum eosinophilia and exhaled nitric oxide), bronchial hyperresponsiveness (BHR) and asthma control.
\end{abstract}

Methods One hundred and thirty-four patients were recruited from our asthma clinic between January 2004 and September 2005 [mean age: 42 years, mean forced expiratory volume in $1 \mathrm{~s}\left(\mathrm{FEV}_{1}\right)$ : 86\% predicted]. Eighty-six of them were treated by inhaled corticosteroids, 99 were atopic and 23 were current smokers. They all underwent detailed investigations including fractional-exhaled nitric oxide $\left(\mathrm{FE}_{\mathrm{N} 0}\right)$ measurement, sputum induction and methacholine challenge when $\mathrm{FEV}_{1}$ was $>70 \%$ predicted, and filled in a validated asthma control questionnaire (ACQ6 Juniper).

Results When dividing patients into the three groups according to their level of asthma control determined by ACQ [well-controlled asthma (ACQ score $\leq 0.75)$, borderline $(0.75<$ ACQ score < 1.5) and uncontrolled asthma (ACQ score $\geq 1.5)]$, it appeared that uncontrolled asthmatics had a greater BHR to methacholine and sputum eosinophilia than controlled asthma $(P<0.05, P<0.001$, respectively). By contrast, we failed to show significant differences in the $\mathrm{FE}_{\mathrm{N} 0}$ levels between the groups. With receiver-operating characteristic curves for differentiating uncontrolled $(\mathrm{ACQ} \geq 1.5$ ) from controlled and borderline (ACQ < 1.5) asthma, sputum eosinophilia and methacholine responsiveness were found to be more accurate than $\mathrm{FE}_{\mathrm{N} 0}$ (area under the curve: $0.72,0.72$ and 0.59 , respectively).

Conclusion In a broad spectrum of asthmatics encountered in clinical practice, sputum eosinophilia and methacholine bronchial hyperresponsiveness, but not $\mathrm{FE}_{\mathrm{N} 0}$, are associated with uncontrolled asthma.

Keywords : asthma control ; exhaled NO ; methacholine responsiveness ; sputum eosinophils

\section{Introduction}

A recent update of the GINA has placed emphasis on the concept of asthma control as being the key target of the treatment. There are several validated questionnaires to measure asthma control. Among these, asthma control questionnaire (ACQ) Juniper is certainly one of the best validated. In its original form, it takes into account not only day and night symptoms and a $\left(\beta_{2}\right.$-agonist as needed but also the baseline airway calibre measured by forced expiratory volume in $1 \mathrm{~s}\left(\mathrm{FEV}_{1}[1]\right.$. Furthermore, shortened versions deleting either the $\mathrm{FEV}_{1}$ item and/or the $\left(\beta_{2}\right.$-agonist consumption item were shown to provide similar information on the level of asthma control achieved by treatment [2].

Recent studies have indicated that uncontrolled asthma may be associated with increased airways inflammation as reflected by increased exhaled NO levels [3] or high sputum eosinophil counts [4, 5]. Besides airway inflammation, asthma control is likely to be influenced by the magnitude of bronchial hyperresponsiveness, the key functional abnormality in asthma. The extent of bronchial hyperresponsiveness (BHR) towards direct agents in asthma was shown to relate to the severity of the disease as defined by the medication needed to obtain disease control [6], and targeting hyperresponsiveness to adjust the maintenance dose of inhaled corticoids resulted in a reduction of mild asthma exacerbations [7]. Despite being somewhat interrelated [8,9] BHR to methacholine and airways inflammation reflect different dimensions in asthma [10]. Very few studies, however, have compared the strength of the association between the lack of asthma control and the magnitude of BHR and 
airway inflammation. Besides airway inflammation and hyperresponsiveness, it is increasingly recognized that additional factors like chronic rhinosinusopathy, anxiety and depression may contribute to poor asthma control [11]. These factors might actually dilute the real influence of airway inflammation and BHR on clinical disease expression.

The purpose of our study was to assess, in a large and unselected population of asthmatics, the relationships between asthma control on the one hand and methacholine BHR and exhaled NO and sputum eosinophils on the other. The study was performed on asthmatics encountered in daily practice recruited from our asthma clinic as they come without excluding those who were already receiving inhaled corticosteroid treatment, current smokers or those experiencing an asthma exacerbation at the time of the investigations. The population was a mix of newly diagnosed asthma, together with patients with a well-established diagnosis whose disease duration was variable.

\section{Methods}

\section{Patients}

For this study, 134 consecutive asthmatics seen between January 2004 and September 2005 and whose functional and demographic characteristics are given in Table 1 were recruited from our asthma clinic. The majority of patients (86/134 - 64\%) were already receiving current treatment with inhaled corticoids for more than 4 weeks before entering the study. Asthma was defined by the presence of recurrent symptoms of breathlessness, cough or wheezing associated with BHR to methacholine (when $\mathrm{FEV}_{1}>70 \%$ predicted) or/and a significant reversibility to inhaled salbutamol (when $\mathrm{FEV}_{1}<80 \%$ predicted) at a moment of the medical history. The demonstration of BHR was based on a positive methacholine challenge defined as a provocative concentration of methacholine causing a decline in $\mathrm{FEV}_{1}$ of $20 \%$ from baseline $(\mathrm{PC} 20 \mathrm{M}) \leq 16 \mathrm{mg} / \mathrm{mL}$. A significant reversibility of $\mathrm{FEV}_{1}$ was defined as a broncho dilation $>12 \%$ after $400 \mu \mathrm{g}$ inhaled salbutamol pMDI. Atopy was defined as a positive skin prick test reaction (weal $\geq 3 \mathrm{~mm}$ compared with control) to common aeroallergens of our area (house dust mites, cat and dog dander, grass, tree and weed pollens and moulds).

Table 1. Demographic and functional patient characteristics

Well-controlled ACQ $<0.75$

$$
n=31
$$

Borderline ACQ 0.75-1.49

$$
n=32
$$

$47 \pm 12$

$16 / 16$

$\operatorname{Sex}(\mathrm{M} / \mathrm{F})$

Tobacco (mean pack-years)

Skin prick test ${ }^{+}$

Steroid treatment

Inhaled steroid dose ( $\mu \mathrm{g} /$ day)

Oral steroid dose (mg/day)

$\mathrm{FEV}_{1}(\%$ predicted $)$

$\mathrm{FEV}_{1} / \mathrm{FVC}(\%)$

PC20M (mg/mL)

Dose-response slope $(\% / \mu \mathrm{mol})$

$\mathrm{FE}_{\mathrm{N} 0}$ (p.p.b.)

Sputum eosinophils (\%)

\section{$40 \pm 13$}

$16 / 15$

$1 \mathrm{CS}$ and 10 exS (10.2) $28(90 \%)$

$20 / 31(64 \%)$

$635(0-2000)$

0

$101 \pm 11$

$80.6 \pm 4.5$

$6.3(0.17-16)$

0.00113

(0.00011-0.1089)

$47.9(11.4-130)$

$0.4(0-31.2)$
Uncontrolled ACQ $\geq 1.5$

$n=71$

$F E V_{l}, F E V_{l} / F V C$ are expressed as mean $\pm S D$ while DRS, $F E_{N o}$ and sputum eosinophil count are expressed as median (range); PC20M is

expressed as the geometric mean (range).

$* P<0.001$ as compared with well controlled.

$* P<0.05$ as compared with well controlled.

$* * P<0.05$ as compared with borderline.

$\mathrm{FE}_{\mathrm{N} 0}$, fractional exhaled nitric oxide; $\mathrm{ACQ}$, asthma control questionnaire; $\mathrm{FVC}$, forced vital capacity; $\mathrm{FEV}_{1 ;}$ forced expiratory volume in $1 \mathrm{~s}$;

SD, standard deviation; DRS, dose-response slope; PC20M, decline in $\mathrm{FEV}_{1}$ of $20 \%$ from baseline; CS, current smokers; exS, ex-smokers. 


\section{Study design}

The patients attended our asthma clinic on 1 day, during which they filled in an ACQ and underwent, in this order, an exhaled NO measurement, a methacholine challenge (when $\mathrm{FEV}_{1}$ was $>70 \%$ predicted after stopping a short-acting ( $\beta_{2}$-agonist for $8 \mathrm{~h}$ and a long-acting ( $\beta_{2}$-agonist for $24 \mathrm{~h}$ ) and a sputum induction. The study was approved by our local ethics committee and subjects gave their informed consent.

\section{Asthma control}

The degree of asthma control was evaluated by the ACQ score from the six-item Juniper ACQ questionnaire deleting the $\mathrm{FEV}_{1}$ from the original questionnaire [2] $(0=$ totally controlled and $6=$ severely uncontrolled $)$. ACQ6 was chosen in order to avoid the mathematical influence of baseline airway calibre on the level of BHR. Patients were considered 'well controlled' when the ACQ score was lower than 0.75 and 'uncontrolled' when the ACQ score was > 1.5. Between these two values, the control was assumed to be 'borderline'. These values were chosen in accordance with the analysis derived from the GOAL study as published by Juniper [12].

\section{Exhaled nitric oxide}

Exhaled nitric oxide was measured by a chemolumines-cence analyser (NIOX, Aerocrine, Stockholm, Sweden) at a flow rate of $50 \mathrm{~mL} / \mathrm{s}$, in accordance with the recommendations of the ATS/ERS task force [13]. The measurement was performed before spirometry and methacholine challenge.

\section{Methacholine challenge}

Spirometry was performed using an electronic spirometer connected in real time to a computer (Spirobank, MIR, Rome, Italy). All manoeuvres were repeated three times and the best $\mathrm{FEV}_{1}$ value was selected by the software program (Winspiro, MIR). Methacholine challenge was performed according to a slightly modified Cockroft's method. Patients successively inhaled by tidal breathing for $2 \mathrm{~min}$ fourfold increasing concentrations of methacholine chloride from 0.06 to $16 \mathrm{mg} / \mathrm{mL}$ as described previously [8]. The aerosol was generated by a jet nebulizer (Hudson, Temecula, CA, USA), whose characteristics were described previously [14]. The provocative concentration of methacholine causing PC20M was calculated by linear interpolation from the dose-response curve. Furthermore, in order to express responsiveness as a continuous variable without censoring subjects, methacholine responsiveness was also expressed as a dose-response slope (DRS) and expressed as \% $\mathrm{FEV}_{1}$ fall/cumulative $\mu \mathrm{mol}$ methacholine. After the provocative challenge, each patient inhaled $400 \mu \mathrm{g}$ salbutamol given by a metered dose inhaler through a spacer, and the sputum induction was started 30 min later.

\section{Sputum induction and processing}

After premedication of the subjects with $400 \mu \mathrm{g}$ inhaled salbutamol (pMDI+spacer), sputum was induced by inhalation of a hypertonic saline ( $\mathrm{NaCl} 4.5 \%)$ combined with additional salbutamol [15] delivered by an ultrasonic nebulizer (Ultra-Neb 2000, De Vilbiss, Somerset, PA, USA) with an output set at $0.9 \mathrm{~mL} / \mathrm{min}$. When post-bronchodilation $\mathrm{FEV}_{1}$ was lower than $65 \%$ of the predicted value, induction was performed with physiologic fluid $(\mathrm{NaCl} 0.9 \%)$ combined with salbutamol. Each subject inhaled the aerosol for three consecutive periods of $5 \mathrm{~min}$ for a total time of $15 \mathrm{~min}$. For safety, $\mathrm{FEV}_{1}$ was monitored every $5 \mathrm{~min}$ and the induction was stopped when $\mathrm{FEV}_{1}$ delined by $>20 \%$ from the post-bronchodilation value.

The whole sputum was collected in a plastic container, weighed and homogenized by adding three volumes of PBS, vortexed for $30 \mathrm{~s}$ and centrifuged at $800 \mathrm{~g}$ for $10 \mathrm{~min}$ at $4{ }^{\circ} \mathrm{C}$. The supernatant was separated from a cell pellet, which was resuspended in a solution containing $5 \mathrm{mM}$ DTT without $\mathrm{Ca}^{2+}$ and $\mathrm{Mg}^{2+}$, filtered and used to perform squamous and total cell count using a manual haemocytometer. Cell viability was checked by trypan blue exclusion. The differential performed on cytospins stained with Diff-Quick after counting 500 cells.

\section{Statistical analysis}

Comparisons between the three groups were performed using the Kruskall-Wallis test, followed, when significance emerged, by Dunn's test for pairwise comparisons. Correlations were tested using the Spearman coefficient of correlation. Receiver-operating characteristic (ROC) curves were constructed to define the accuracy of $\mathrm{FEV}_{1}, \mathrm{FEV}_{1}$ /forced vital capacity $(\mathrm{FVC})$, fractional-exhaled nitric oxide $\left(\mathrm{FE}_{\mathrm{N} 0}\right)$, sputum eosinophilia and methacholine BHR to differentiate controlled and borderline from uncontrolled asthma. Cut-point was defined as the value allowing to correctly classify most of the events. $P$-values $<0.05$ were considered as 
statistically significant.

\section{Results}

Overall exhaled NO and sputum eosinophil percentage were correlated $(r=0.54, P<0.0001)$, and both sputum eosinophilia and exhaled NO were inversely correlated with PC20 M $(r=-0.41$ and $P<0.001$ and $r=-0.34$ and $P<0.01$, respectively).

When dividing patients in to three groups according to their asthma control as determined by the ACQ [wellcontrolled asthma (ACQ score $\leq 0.75)$, borderline $(0.75<$ ACQ score $<1.5)$ and uncontrolled asthma (ACQ score $\geq 1.5)$ ], we found that uncontrolled asthmatics displayed a greater bronchial responsiveness to methacholine than those who were controlled $(P<0.05)$ (Fig. 1a, Table 1). We failed to show significant differences in $\mathrm{FE}_{\mathrm{N} 0}$ between the three groups (Fig. 2a, Table 1) while sputum eosinophilia was significantly higher in the uncontrolled group than in the controlled and the borderline group $(P<0.001$ and $P<0.05$, respectively) (Fig. 3a, Table 1). How treatment with inhaled corticoids may influence the relationships between these variables and asthma control is shown in Figs $1 b, 2 b$ and $3 b$. Among patients regularly receiving inhaled corticoids, uncontrolled asthmatics still exhibited greater methacholine BHR than their controlled or borderline counterparts (Fig. 1b). $\mathrm{FE}_{\mathrm{N} 0}$ values were not significantly higher in the uncontrolled corticosteroid-naïve group as compared with the other groups not treated with corticoids. However, it clearly appeared that patients receiving inhaled corticoids had lower $\mathrm{FE}_{\mathrm{N} 0}$ than those without corticoids irrespective of the level of asthma control (Fig. 2b). As for sputum eosinophils, Fig. $3 \mathrm{~b}$ clearly shows that treatment with inhaled corticoids failed to normalize sputum cell counts when asthma remained uncontrolled.

Fig. 1. (a) Methacholine bronchial hyperresponsiveness expressed as the dose-response slope according to asthma control assessed by the mean Juniper asthma control questionnaire (ACQ)6 score. Bars represent the median, (b) Represents corticosteroid-treated and corticosteroid-naïve patients separately.
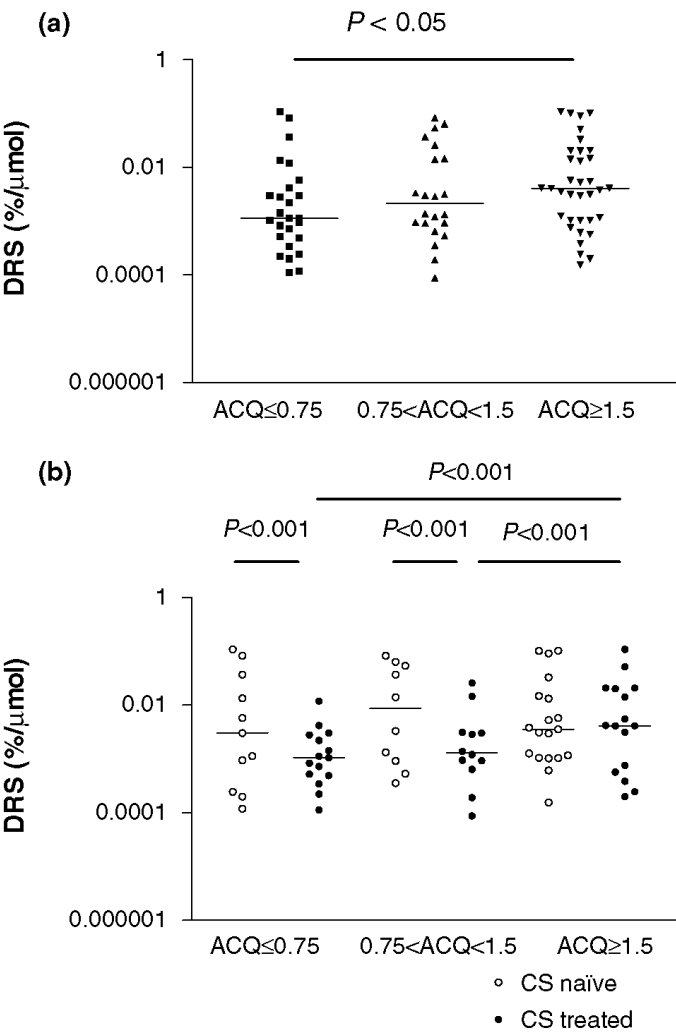
Fig. 2. (a) Exhaled nitric oxide values according to the level of asthma control assessed by the mean Juniper asthma control questionnaire (ACQ)6 score. Bars represent the median, (b) Represents corticosteroid-treated and corticosteroid-naive patients separately.

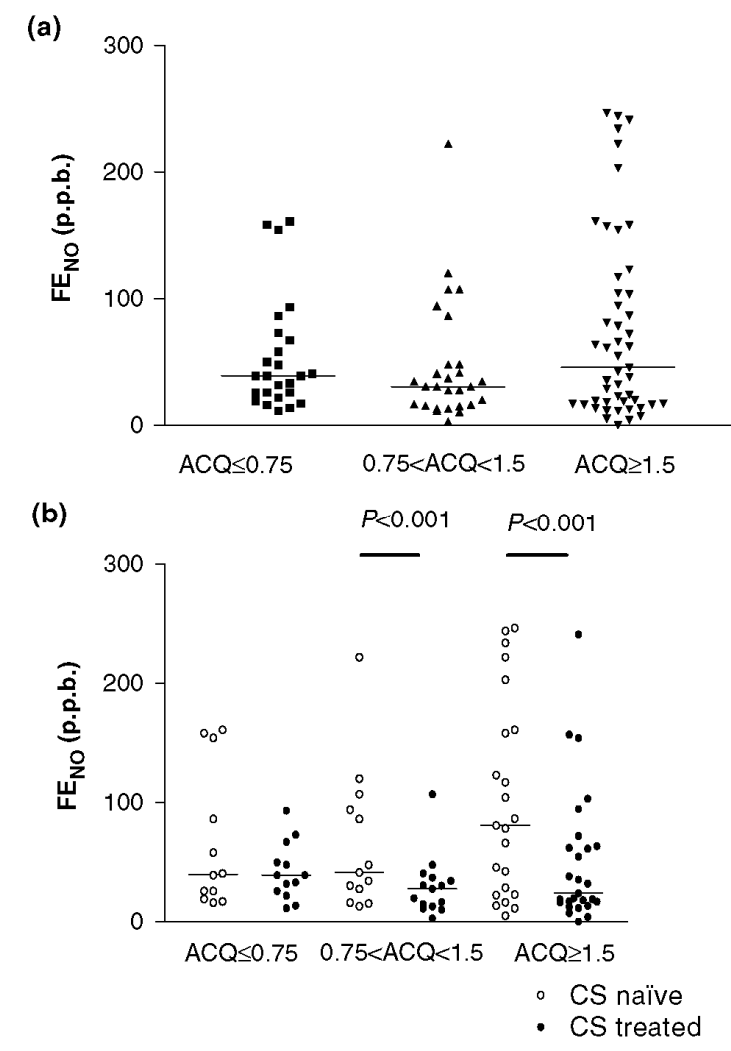

Fig. 3. (a) Sputum eosinophil count according to asthma control assessed by the mean Juniper asthma control questionnaire (ACQ)6 score. Bars represent the median, (b) Represents corticosteroid-treated and corticosteroid-nä̈ve patients separately.
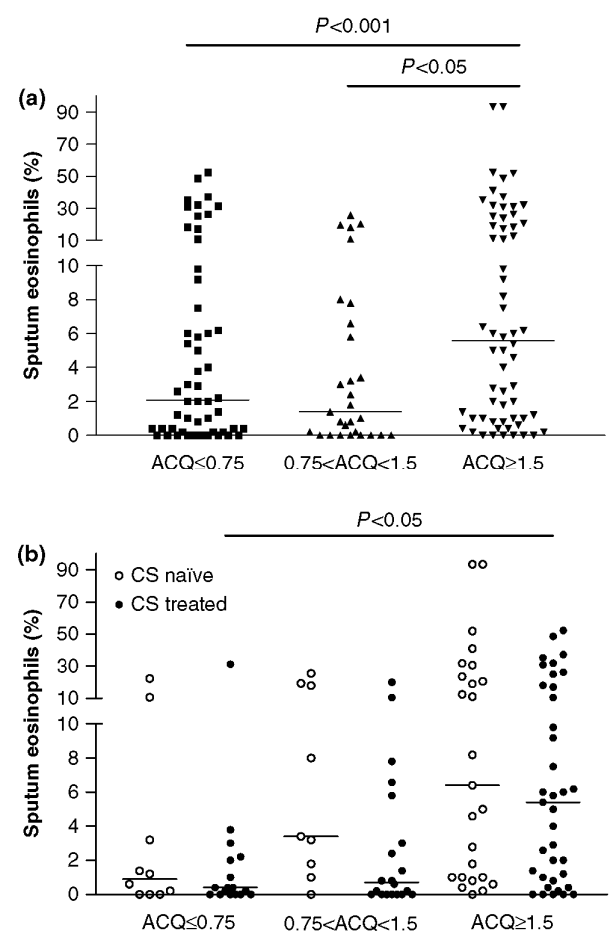
Fig. 4. Receiver-operating characteristic curves of dose-response slope (DRS) (upper panel), fractional exhaled nitric oxide $\left(F E_{N o}\right)$ (middle panel) and sputum eosinophil count (lower panel) in differentiating uncontrolled [asthma control questionnaire $(A C Q) \geq 1.5$ ] from controlled and borderline asthma $(A C Q<1.5)$.
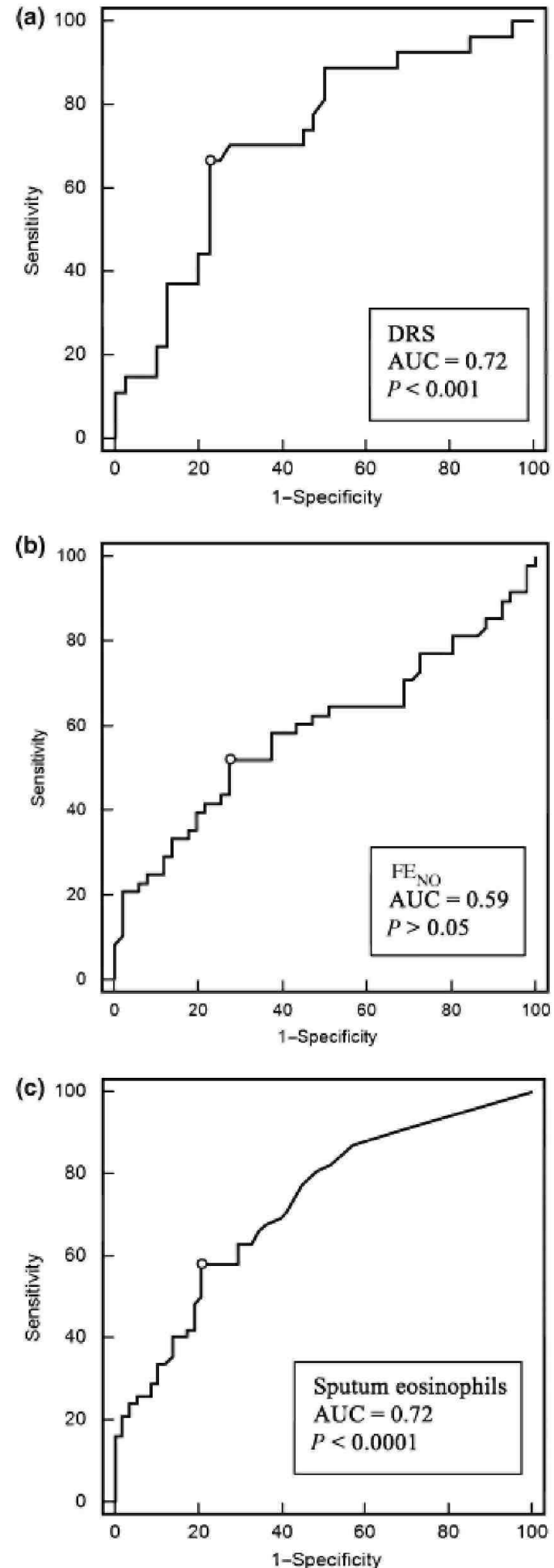
Fig. 5. Receiver-operating characteristic curves of dose-response slope (DRS) (upper panel), fractional exhaled nitric oxide $\left(F E_{N o}\right)$ (middle panel) and sputum eosinophil (lower panel) count in differentiating uncontrolled (asthma control questionnaire ACQ > 1.5) from controlled and borderline asthma $(A C Q<1.5)$ inpatients not receiving inhaled corticosteroids.
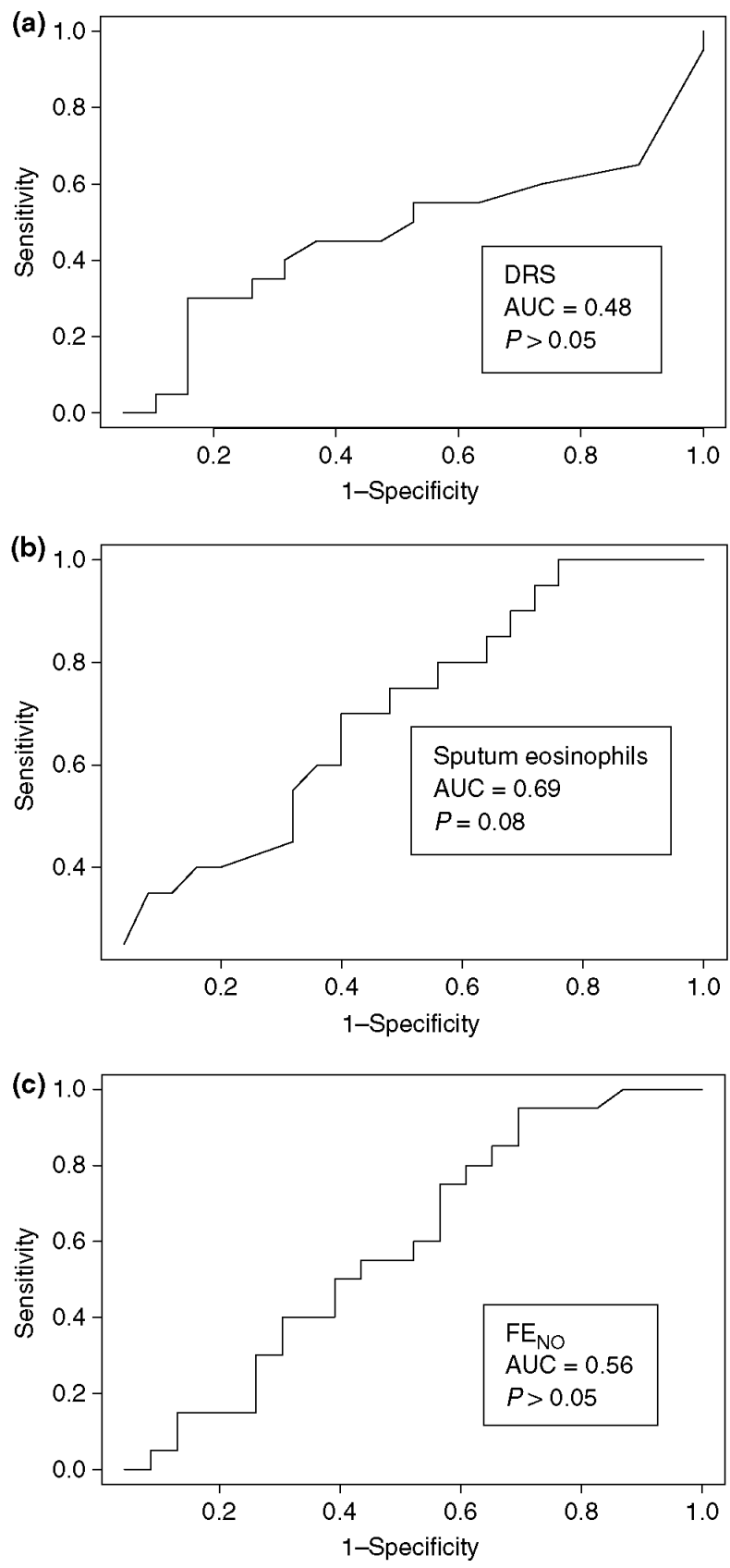

ROC curve analysis shows that the sputum eosinophil count and methacholine responsiveness were better than $\mathrm{FE}_{\mathrm{N} 0}$ for identifying uncontrolled asthmatics [area under the curve (AUC) $=0.72 \mathrm{vs}$. 0.72 vs. 0.59 , respectively) (Fig. 4). ROC curves for baseline lung calibre as reflected by $\mathrm{FEV}_{1}$ and the ratio $\mathrm{FEV}_{1} / \mathrm{FVC}$ yielded AUC reaching 0.62 and 0.63 , respectively (Table 2).

ROC curves in asthmatics not receiving inhaled corticoids indicate that the sputum eosinophil count remained the best variable to predict uncontrolled asthma while methacholine responsiveness and $\mathrm{FE}_{\mathrm{N} 0}$ were poor in this case (Fig. 5).

The 'best' cut-off value for differentiating uncontrolled from controlled and borderline asthma was $3.8 \%$ for sputum eosinophilia with a sensitivity and a specificity of $58 \%$ and $79 \%$, respectively (Table 2). Likewise, the 
cut-off value for PC20M was $3.4 \mathrm{mg} / \mathrm{mL}$ with a sensitivity and a specificity of $70 \%$. As for $\mathrm{FEV}_{1}$ and $\mathrm{FEV} / \mathrm{FWC}$, the best cut-off values were $69 \%$ predicted and $84 \%$, respectively (Table 2 ).

A bronchodilation test was performed in only 24 patients; 21 out of them were found in the uncontrolled group. Among these patients, the extent of reversibility was correlated to the ACQ values $(r=0.36, P=0.08)$.

Six patients were considered as having severe exacerbation by the time of the study based on the need to prescribe oral corticoids. Mean \pm SEM ACQ was 4.2 (3.4-4.9) and the median (range) sputum eosinophil count was $22 \%(1.2-48) . \mathrm{FE}_{\mathrm{N} 0}$ was measurable in only one of those patients (241 p.p.b.).

Table 2. Diagnostic performance of baseline lung function, methacholine hyperresponsiveness and airway inflammatory parameters to identify uncontrolled asthma $(A C Q \geq 1.5)$

\begin{tabular}{lccccc}
\hline & AUC & $P$-value & Cut-off value & Sensitivity (\%) & Specificity (\%) \\
\hline FEV $_{1}(\%$ predicted) & 0.62 & $<0.05$ & 69 & 31 & 94 \\
FEV $_{1} / \mathrm{FVC}(\%)$ & 0.63 & $<0.01$ & 84 & 82 & 43 \\
$\mathrm{PC} 20 \mathrm{M}(\mathrm{mg} / \mathrm{mL})$ & 0.69 & $<0.005$ & 3.4 & 70 & 70 \\
DRS (o/o/nmol) & 0.72 & $<0.001$ & 0.0035 & 67 & 77 \\
FE $_{\mathrm{N} 0}$ (p.p.b.) & 0.59 & $>0.05$ & 54.7 & 52 & 73 \\
Sputum eosinophils $(\%)$ & 0.72 & $<0.0001$ & 3.8 & 58 & 79
\end{tabular}

FEV $V_{l}$, forced expiratory volume in $1 \mathrm{~s} ; \mathrm{FVC}$, forced vital capacity; ACQ, asthma control questionnaire; DRS, dose-response slope; AUC, area under the curve; $P C 20 M$, decline in $F E V_{I}$ of $20 \%$ from baseline.

\section{Discussion}

This cross-sectional study, conducted on a large and heterogeneous population of asthmatics, shows that uncontrolled asthma is associated with the degree of sputum eosinophilia and methacholine BHR but not with the levels of exhaled NO.

The relationship between sputum eosinophilia and poor asthma control comes as a confirmation of previous data reported by Romagnoli et al. [5] on a limited series of patients and is keeping with the role attributed to airway eosinophils in asthma exacerbation occurring in moderate to severe asthma [16]. Our finding points to a threshold of $4 \%$ sputum eosinophilia as the best level to predict uncontrolled asthma. This threshold is only slightly higher than the threshold recognized to identity an abnormally high sputum eosinophil percentage, which lies between $2 \%$ and $3 \%$ according to a study performed on healthy subjects $[4,8,17-19]$. This indicates that the appearance of a modest eosinophilic airway inflammation in asthma may rapidly be associated with symptom expression of the disease. It is of interest to note that the association of sputum eosinophils with uncontrolled asthma clearly persisted when considering patients regularly treated with inhaled corticoids. Although inhaled corticoids are often extremely effective in reducing eosinophilic inflammation in mild asthmatics tightly selected for controlled drug trials $[20,21]$, our data indicate that the picture may not be the same in patients encountered in real life. The reasons for this may be numerous and may include factors independent of the drug efficacy itself such as poor adherence or awkward device utilization but also factors that cause true resistance to the drug such as active smoking [22]. As demonstrated by the overlap in the sputum eosinophil count between our different groups, the link between eosinophilic inflammation and asthma symptoms is of course not absolute. A recent cross-sectional study using a cluster analysis on a large series of asthmatics seen in secondary care has clearly pointed to a subgroup of patients with few symptoms but an intense sputum eosinophilia while another subgroup was characterized by a high symptom score without sputum eosinophilia [23].

In contrast to sputum eosinophilia, it appears that exhaled NO was poorly related to the level of asthma control. Although it may seem to be surprising in view of previous data [24, 25], it should be kept in mind that our study was cross-sectional and conducted in a real-life setting including all types of asthmatics as they come to the asthma clinic. It includes a majority of patients already treated with inhaled corticoids, with some of them being current smokers, factors that are recognized to decrease the level of exhaled NO [26, 27] and therefore potentially altering the relationship between exhaled $\mathrm{NO}$ and asthma control. As pointed out by Bates et al. $\mathrm{FE}_{\mathrm{N} 0}$ reacts particularly quickly and well before symptoms to a treatment with inhaled corticoids [28]. However, neither the percentage of patients treated with inhaled corticoids nor that of current smokers was significantly 
different between the uncontrolled asthmatics vs. the other two groups. Our data clearly showed that exhaled NO levels were more influenced by inhaled corticoids than by the level of asthma control. The persistence of a significant association between eosinophils, but not between $\mathrm{FE}_{\mathrm{N} 0}$ and asthma control, might be linked to the different sensitivities of the two inflammatory markers to the doses of inhaled corticoids. In contrast to most asthma studies, here we did not systematically exclude those patients who had symptoms of viral infection during the 4 weeks preceding the visit. These infections are a well-established cause of asthma exacerbation [29]. Nevertheless, as viral infections are thought to increase exhaled NO together with asthma symptoms [30], they are not supposed to break the relationship between exhaled NO and asthma control. On the other hand, several well-conducted longitudinal studies found exhaled NO to be less predictive of asthma control deterioration than sputum eosinophils, when stepping down inhaled corticoids [31-33]. Taken together, these data lead us to consider the sputum eosinophil count, although being a less convenient technique, as a more robust inflammatory marker than exhaled NO in asthmatics encountered in daily practice. Our data support the recommendation of using sputum eosinophil counts to assess global asthma control [34].

The degree of methacholine BHR was found to be proportional to the level of asthma control, with lower PC20 and greater DRS values in uncontrolled asthmatics. The extent of responsiveness to methacholine is thought to mainly reflect abnormal behaviour of smooth muscle and/or airway remodelling rather than airway inflammation, which is better assessed by responsiveness to indirect mediators like adenosine [35]. It is noteworthy that approximately one-third of our controlled asthmatics had normalized their BHR with PC20 > $16 \mathrm{mg} / \mathrm{mL}$ thanks to a regular treatment with inhaled corticoids. This is in keeping with the effect of a long-term treatment with inhaled corticoids on bronchial responsiveness towards direct constricting agents, which, on average, improves the PC20 by 1-2 doubling dilution [36, 37]. The greater BHR found in uncontrolled asthmatics suggests that airway instability is a factor of poor asthma control. This concept is supported by the demonstration that taking into account the level of BHR when adjusting the dose of inhaled corticoids results in a reduction of mild exacerbations in asthmatics [7]. Interestingly, the association between hyperresponsiveness and uncontrolled asthma is essentially observed in those patients already receiving inhaled corticoids. This would suggest that a component of methacholine responsiveness that is poorly responsive to corticoids (remodelling part) contributes to asthma symptoms. Thermoplasty, a new technique for asthma treatment that targets airway smooth muscle by radio-frequency, may well improve asthma control through an attenuation of BHR [38].

Although providing significant ROC curves in differentiating uncontrolled from controlled asthma, $\mathrm{FEV}_{1}$ and the ratio $\mathrm{FEV}_{1} / \mathrm{FVC}$ proved to be less accurate than methacholine responsiveness and sputum eosinophils to predict the lack of control of asthma symptoms. This emphasizes the need to go beyond spirometry when dealing with uncontrolled asthmatics.

In conclusion, our cross-sectional study shows that, in a large heterogeneous population of mild to moderate asthmatics encountered in daily practice, uncontrolled asthma is associated with increased BHR to methacholine and an increased sputum eosinophil count, but not with increased exhaled NO. This should prompt the clinician to consider measuring these parameters when asthma remains uncontrolled despite treatment with inhaled corticoids.

\title{
Acknowledgements
}

This work was supported by an Interuniversity Attraction Poles (IAP) project P6/P35.

\section{References}

1 Juniper EF, O'Byrne PM, Guyatt GH, Ferrie PJ, King DR. Development and validation of a questionnaire to measure asthma control. EurRespir J 1999; 14:902-7.

\author{
2 Juniper EF, Svensson K, Mork AC, Stahl E. Measurement properties and interpretation of three shortened versions of the asthma control \\ questionnaire. Respir Med 2005; 99:553-8.
}

3 Sippel JM, Holden WE, Tilles SA et al. Exhaled nitric oxide levels correlate with measures of disease control in asthma. J Allergy Clin Immunol 2000; 106:645-50.

4 Louis R, Lau LC, Bron AO, Roldaan AC, Radermecker M, Djukanovic R. The relationship between airways inflammation and asthma severity. Am J Respir Crit Care Med 2000; 161:9-16.

5 Romagnoli M, Vachier I, Tarodo dlF et al. Eosinophilic inflammation in sputum of poorly controlled asthmatics. Eur Respir J 2002; 20:1370-7. 
6 Juniper EF, Frith PA, Hargreave FE. Airway responsiveness to histamine and methacholine: relationship to minimum treatment to control symptoms of asthma. Thorax 1981; 36:575-9.

7 Sont JK, Willems LN, Bel EH, van Krieken JH, Vandenbroucke JP, Sterk PJ. Clinical control and histopathologic outcome of asthma when using airway hyperresponsiveness as an additional guide to long-term treatment. The AMPUL Study Group. Am J Respir Crit Care Med 1999; 159:1043-51.

8 Louis R, Sele J, Henket M et al. Sputum eosinophil count in a large population of patients with mild to moderate steroid-naive asthma: distribution and relationship with methacholine bronchial hyperresponsiveness. Allergy 2002; 57:907-12.

9 van den BM, Meijer RJ, Kerstjens HA et at PC(20) adenosine 5'-monophosphate is more closely associated with airway inflammation in asthma than PC(20) methacholine. Am J Respir Crit Care Med 2001; 163:1546-50.

10 Rosi E, Ronchi MC, Grazzini M, Duranti R, Scano G. Sputum analysis, bronchial hyperresponsiveness, and airway function in asthma: results of a factor analysis. J Allergy Clin Immunol 1999; 103:232-7.

11 ten Brinke A, Sterk PJ, Masclee AA et al. Risk factors of frequent exacerbations in difficult-to-treat asthma. Eur Respir J 2005; 26:812-

12 Juniper EF, Bousquet J, Abetz L, Bateman ED. Identifying 'well-controlled' and 'not well-controlled' asthma using the Asthma Control Questionnaire. Respir Med 2006; 100:616-21.

13 ATS/ERS recommendations for standardized procedures for the online and offline measurement of exhaled lower respiratory nitric oxide and nasal nitric oxide, 2005. Am J Respir Crit Care Med 2005; 171:912-30.

14 Louis R, Bury T, Corhay JL, Radermecker MF. Acute bronchial and hematologic effects following inhalation of a single dose of PAF. Comparison between asthmatics and normal subjects. Chest 1994; 106:1094-9.

15 Delvaux M, Henket M, Lau L et al. Nebulised salbutamol administered during sputum induction improves bronchoprotec-tion in patients with asthma. Thorax 2004; 59:111-5.

16 Green RH, Brightling CE, McKenna S et al. Asthma exacerbations and sputum eosinophil counts: a randomised controlled trial. Lancet $2002 ; 360: 1715-21$

17 Belda J, Leigh R, Parameswaran K, O'Byrne PM, Sears MR, Hargreave FE. Induced sputum cell counts in healthy adults. Am J Respir Crit Care Med 2000; 161:475-8.

18 Green RH, Brightling CE, Woltmann G, Parker D, Wardlaw AJ, Pavord ID. Analysis of induced sputum in adults with asthma: identification of subgroup with isolated sputum neutrophilia and poor response to inhaled corticosteroids. Thorax 2002; 57: 875-9.

19 Spanevello A, Confalonieri M, Sulotto F et al. Induced sputum cellularity. Reference values and distribution in normal volunteers. Am J Respir Crit Care Med 2000; 162:1172-4.

20 Aldridge RE, Hancox RJ, Robin TD et al. Effects of terbutaline and budesonide on sputum cells and bronchial hyperresponsiveness in asthma. Am J Respir Crit Care Med 2000; 161: 1459-64.

21 Jatakanon A, Lim S, Chung KF, Barnes PJ. An inhaled steroid improves markers of airway inflammation in patients with mild asthma. Eur Respir J 1998; 12:1084-8.

22 Chalmers GW, MacLeod KJ, Little SA, Thomson LI, McSharry CP, Thomson NC. Influence of cigarette smoking on inhaled corticosteroid treatment in mild asthma. Thorax 2002; 57: 226-30.

23 Haldar P, Pavord ID, Shaw DE et al. Cluster analysis and clinical asthma phenotypes. Am J Respir Crit Care Med 2008; 178: $218-24$.

24 Sippel JM, Holden WE, Tilles SA et al. Exhaled nitric oxide levels correlate with measures of disease control in asthma. J Allergy Clin Immunol 2000; 106:645-50

25 Michils A, Baldassarre S, Van Muylem A. Exhaled nitric oxide and asthma control: a longitudinal study in unselected patients. Eur Respir J 2008; 31:539-46.

26 Kharitonov SA, Yates DH, Barnes PJ. Inhaled glucocorticoids decrease nitric oxide in exhaled air of asthmatic patients. Am J Respir Crit Care Med 1996; 153:454-7.

27 Verleden GM, Dupont LI, Verpeut AC, Demedts MG. The effect of cigarette smoking on exhaled nitric oxide in mild steroid-naive asthmatics. Chest 1999; 116:59-64.

28 Bates CA, Silkoff PE. Exhaled nitric oxide in asthma: from bench to bedside. J Allergy Clin Immunol 2003; 111:256-62.

29 Johnston SL. Innate immunity in the pathogenesis of virus-induced asthma exacerbations. Proc Am Thorac Soc 2007; 4: $267-70$. 
Published in : Clinical \& Experimental Allergy : Journal of the British Society for Allergy \& Clinical Immunology (2009) Status : Postprint (Author's version)

30 Kharitonov SA, Yates D, Barnes PJ. Increased nitric oxide in exhaled air of normal human subjects with upper respiratory tract infections. Eur Respir J 1995; 8:295-7.

31 Deykin A, Lazarus SC, Fahy JV et al. Sputum eosinophil counts predict asthma control after discontinuation of inhaled corticosteroids. J Allergy Clin Immunol 2005; 115:720-7.

32 Jatakanon A, Lim S, Barnes PJ. Changes in sputum eosinophils predict loss of asthma control. Am J Respir Crit Care Med 2000; 161:6472.

33 Leuppi JD, Salome CM, Jenkins CR et al. Predictive markers of asthma exacerbation during stepwise dose reduction of inhaled corticosteroids. Am J Respir Crit Care Med 2001; 163:406-12.

34 Boulet LP, Boulet V, Milot J. How should we quantify asthma control? A proposal. Chest 2002; 122:2217-23.

35 Joos GF, O'Connor B, Anderson SD et al. Indirect airway challenges. Eur Respir J 2003; 21:1050-68.

36 Juniper EF, Kline PA, Vanzieleghem MA, Ramsdale EH, O'Byrne PM, Hargreave FE. Effect of long-term treatment with an inhaled corticosteroid (budesonide) on airway hyperresponsiveness and clinical asthma in nonsteroid-dependent asthmatics. Am Rev Respir Dis 1990; 142:832-6

37 van Grunsven PM, van Schayck CP, Molema J, Akkermans RP, van Weel C. Effect of inhaled corticosteroids on bronchial responsiveness in patients with "corticosteroid nai've" mild asthma: a meta-analysis. Thorax 1999; 54:316-22.

38 Cox G, Miller JD, McWilliams A, Fitzgerald JM, Lam S. Bronchial thermoplasty for asthma. Am J Respir Crit Care Med 2006; 173:965- 